\title{
A FARMÁCIA DE CAMÕES
}

\section{CAMOENS' PHARMACY}

Rafael Santana ${ }^{1}$

\section{RESUMO}

Camões nunca escreveu ensaios. A sua poesia evidencia contudo uma dicção acentuadamente ensaística, inscrita numa dialética marcada pela presença de antinomias como imperialismo e anti-imperialismo, discurso e contradiscurso. Iconoclasta, no sentido mesmo etimológico daquela que rompe ícones, a poesia do grande vate utiliza-se quer da herança cultural do código de amor cortês, quer do petrarquismo, quer do neoplatonismo cristão como referências passíveis de serem comentadas, questionadas, postas em xeque. Este artigo postula a hipótese de a poesia camoniana expressar um veio filosófico ensaístico, constituído na própria materialidade da sua escrita.

PALAVRAS-CHAVE: Camões; ensaio; filosofia.

\begin{abstract}
Camoens never wrote essays. Nonetheless, his poetry exhibits a diction proper of an essay, with a dialectic full of antinomies such as imperialism and anti-imperialism, discourse and counter-discourse. Iconoclastic (in the etymological sense of "destroyer of images"), Camoens' poetry makes use of the cultural heritage of courtly love, Petrarchism and Neoplatonism as frames of reference that may as well be criticized. This paper postulates that the Camonian poetry conveys in the materiality of its writing, as much as an essay, a philosophical message.
\end{abstract}

KEYWORDS: Camoens; essay; philosophy. 
Es hielo abrasador, es fuego helado,

es herida que duele y no se siente,

es un soñado bien, un mal presente,

es un breve descanso muy cansado.

(Francisco de Quevedo)

Em concordância com Camões e em defesa do amor, escreve Francisco de Quevedo: “iEste es el niño Amor, éste es su abismo. / Mirad cuál amistad tendrá con nada / el que en todo es contrario a sí mismo!" (2004, p. 86-87). Na esteira camoniana dos desconcertos amorosos, o poeta barroco aponta igualmente para os paradoxos em que o amor se sustenta. $\mathrm{E}$ se a conclusão do soneto em português sinaliza a impossibilidade de sistematizar num raciocínio lógico convencional os seus efeitos contraditórios, o soneto em espanhol termina por reiterar não menos perplexamente aquilo que em Camões cedera espaço a um instigante questionamento frente à quebra da organicidade silogística: "Mas como causar pode seu favor / nos corações humanos amizade, / se tão contrário a si é o mesmo Amor?" (2005, p. 119).

Onze dos quatorze versos deste poema são compostos por pequenas considerações filosóficas acerca das contrariedades amorosas, construídas sob este preciso raciocínio: tudo o que é contraditório não traz conformidade/amizade; o amor é contraditório; logo, o amor não traz conformidade. Mas a conclusão do soneto não é essa, como bem o sabemos, e fato é que o amor pode, sim, trazer conformidade aos corações humanos, burlando deste modo a tentativa vã de tornar coerente, explicada, devassada, a multiplicidade do seu desconcerto. Por outras palavras, o amor não é explicável porque, desconcertado, escapa a qualquer conceituação tradicional. Seguindo a lógica do seu próprio desconcerto, está sempre a gerar outros desconcertos, a resvalar na contradição da contradição. Assim, se o poema camoniano, por um lado, parece frustrar as expectativas do silogismo, por outro, mantém-se fiel à essência paradoxal do amor, sentimento complexo que, de tão contrário a si, engendra em si mesmo o contrário de si. Oximórico, o amor, inicialmente condenado a ser a causa do sofrimento dos amantes, torna-se ele também no propiciador de uma surpreendente experiência de conformidade por parte daqueles que amam, em que pesem todas as suas contrariedades.

Considero este soneto um verdadeiro ensaio filosófico sobre os estados amorosos. Afinal, da perspectiva sintomatológica a partir da qual era compreendido na Antiguidade Clássica à indagação filosófica do seu paradoxo essencial e/ou existencial, o amor - na mitologia, na filosofia e na arte - é não raro a irrupção discursiva do seu próprio desconcerto, ou melhor, da sua natureza desconcertante e desconcertada. Filho de Póros, deus da abundância, e de Penía, deusa da miséria, o amor é a um só tempo a riqueza e a pobreza; é simultaneamente a mais sublime e a mais degradante 
das experiências humanas; é enfim um constante estado de contradição. Não por acaso de amor falam reiteradas vezes os poetas, seres hipersensíveis, que sabem que amar é antes de tudo viver em estado de poesia. Mais do que isso: que sabem que amar é assumir para si próprios os estados oximóricos da poesia, discurso capaz quer de curar, quer de matar!

Camões e Quevedo escrevem ambos sobre as contrariedades dos estados amorosos, percebendo muito espantados que o amor, no seu caráter absolutamente paradoxal, chega ao surpreendente ponto de ser contrário a si. Tal observação não é nada aleatória e põe em xeque uma tese platônica defendida no Fédon. Questionado sobre a sua teoria da imortalidade da alma e, por conseguinte, da superioridade do espírito quando cotejado ao corpo, Sócrates assinala "que jamais um contrário será contrário a si mesmo" (PLATÃO, 2006, p. 99); assim, de acordo com a perspectiva socrática a alma nunca admitirá o contrário que traz consigo: a morte. E dentre os diversos contrários exemplificados, o mestre de Platão dá destaque à neve e ao fogo, dizendo:

SÓCRATES. - Considera então também isto, a ver se te mostras de acordo comigo: há algo que chamas quente e algo que chamas frio?

CEBES. - Sim.

SÓCRATES. - Acaso é o mesmo que a neve e o fogo?

CEBES. - Não, por Zeus!

SÓCRATES. - Então o quente é uma coisa distinta do fogo e o frio uma coisa distinta da neve?

CEBES. - Sim.

SÓCRATES. - No entanto, creio que, mesmo assim, opinas que a neve, enquanto tal, se recebe calor, jamais voltará a ser o que era, como dizíamos anteriormente, ou seja, neve e calor de uma só vez, senão que, ao aproximar-se o calor ou lhe cederá o posto ou perecerá.

CEBES. - Exato.

SÓCRATES. - E o fogo, por sua vez, ao se lhe aproximar o frio ou retrocederá ou perecerá, mas jamais, recebendo a frieza, se atreverá a ser o que era, ou seja, a ser fogo e frio a um só tempo. (PLATÃO, 2006, p. 99)

Camões é um poeta iconoclasta, no sentido mesmo etimológico da palavra, que é o de romper ícones. Como acentua Helder Macedo (2013), o petrarquismo camoniano é a base do seu antipetrarquismo. Poeta da experiência, para quem os seus amores hão de ser ativos, diga-se, experimentados, o autor de Os Lusíadas amplia as possibilidades amorosas, limitadas, por exemplo, num Dante e num Petrarca, em musas únicas e 
contempladas como Beatriz e Laura, para a pluralidade das várias flamas em que variamente ardeu. E o platonismo e o neoplatonismo cristão são também eles por diversas vezes colocados à prova seja na lírica, seja na épica de Camões. Como vimos, para Platão a neve não pode ser neve e fogo a um só tempo porque, quando o calor se lhe acerca, ela deixa de existir como elemento frio. Do mesmo modo, o fogo, uma vez envolvido pela neve, não poderá jamais ser quente e frio em concomitância. Mas a lógica da filosofia não é a mesma que a da poesia, e nem sequer que a do amor no que tange à experiência! Para Camões o "Amor é um fogo que arde sem se ver" (2005, p. 119); para Quevedo é gelo abrasador, fogo gelado. Ora, nestes dois poetas ibéricos neve e fogo logram os seus contrários sem contudo deixarem de ser neve e fogo enquanto tais, o que desestabiliza a tese platônica de que jamais um contrário será contrário a si mesmo.

Em Camões a contestação desta tese surge não apenas no referido soneto mas também no poder de Vênus de reverter a força dos opostos, "Com que os Pólos gelados acendia, / E tornava do Fogo a esfera, fria" (2006, p. 107); também no "fogo que na branda cera ardia" e que, acendido de outro fogo - o do desejo -, ousa beijar a branca face da amada, queimando destarte "[...] aquela neve / que queima corações e pensamentos" (2005, p. 120); e também no próprio poeta que, em vivo ardor, tremendo está de frio. Tudo isso são diálogos camonianos estabelecidos com Platão: referências muito mais do que reverências.

Camões nunca escreveu ensaios mas, pessoanamente, é como se os escrevesse. Aliás, poucos são os poetas portugueses do seu tempo cuja obra artística expressa um veio filosófico-crítico tão forte, e no seio da própria poesia. E não falo apenas daquelas discussões poético-filosóficas mais canonicamente conhecidas, tais como as apresentadas nos sonetos "Transforma-se o amador na cousa amada" (2005, p. 126) e "Pede o desejo, Dama, que vos veja" (2005, p. 120), que obedecem a uma mesma estrutura lógica que vai da construção de uma suposta defesa do ideário neoplatônico nos quartetos à desconstrução desse mesmo ideário nos tercetos. Em ambos os sonetos a incorporeidade amorosa, requerida quer pelo petrarquismo, quer pelo neoplatonismo cristão, dá lugar a uma contestação que é no fundo a afirmação de uma carnalidade que aristotelicamente, "como matéria simples, busca a forma": desejo ardente, que insiste em se materializar. Em Camões não há conhecimento possível para fora do âmbito da experiência, o que significa dizer que, para ele, conhecer é muitas vezes experimentar. Tal como a "grave pedra", cuja força do desejo, também aristotelicamente, a impele para o centro da natureza, o amor, na sua imensa força de atração, tem o poder de despertar nos amantes um apetite vivo, pulsante, erótico e que - da perspectiva camoniana - não deixa de ser puro! Com efeito, eis a lição apresentada já no pórtico das suas Rimas: “[...] verdades puras são e não defeitos. E sabei que, segundo o amor tiverdes, / tereis o entendimento de meus versos" (2005, p. 117)! 
Camões, poeta experiente no amor, requer para a sua obra leitores amorosamente experimentados... E embora ele próprio afirme ser um artista engenhoso, a quem não "[...] falta na vida honesto estudo, / Com longa esperiencia misturado", coisas que, consoante as suas palavras, "juntas se acham raramente" (2006, p. 355), é ele também quem afirma preferir o saber da experiência ao discurso eloquente dos "Doctos varões", pois “[...] são experiências mais provadas, / e por isso é milhor ter muito visto" (2005, p. 199). Na sedutora viagem iniciática que é a sua escrita, o embate entre cultura e experiência ou, se quisermos, entre teoria e prática, surge a todo momento, como que a sinalizar que, por mais elucidativa que uma hipótese filosófica ou científica possa parecer, ela jamais dará conta de explicar a complexidade de habitar um mundo confuso, regido não pela lógica mas pelo desconcerto. Conhecendo não ter qualquer conhecimento definitivo, bem como a prerrogativa de qualquer verdade que se queira absoluta, Camões, muito modernamente, parece preferir verdades à Verdade:

Os casos vi que os rudos marinheiros,

Que tem por mestra a longa experiência,

Contam por certos sempre e verdadeiros, Julgando as cousas só pola aparência,

E que os que tem juízos mais inteiros, Que só por puro engenho ou por ciência Vem do Mundo os segredos escondidos, Julgam por falsos ou mal entendidos.

Vi, claramente visto, o lume vivo que a marítima gente tem por Santo, Em tempo de tormenta e vento esquivo, De tempestade escura e triste pranto. Não menos foi a todos excessivo Milagre, e cousa, certo, de alto espanto, Ver as nuvens, do mar com largo cano, Sorver as altas águas do Oceano.

Eu o vi certamente (e não presumo Que a vista me enganava): levantar-se No ar um vaporzinho e sutil fumo, E, do vento trazido, rodear-se; De aqui levado um cano ao Pólo sumo Se via, tão delgado, que enxergar-se Dos olhos facilmente não podia; Da matéria das nuvens parecia.

\section{$[\ldots]$}

Mas, despois que de todo se fartou, O pé que tem no mar a si recolhe E pelo céu, chovendo, enfim voou, Por que $c o$ a água a jacente água molhe; Às ondas torna as ondas que tomou, 
Mas o sabor do sal the tira e tolhe.

Vejam agora os sábios na escritura

Que segredos são estes de Natura!

Se os antigos Filósofos, que andaram

Tantas terras, por ver segredos delas,

As maravilhas que eu passei, passaram,

A tão diversos ventos dando as velas,

Que grandes escrituras que deixaram!

Que influição de sinos e de estrelas!

Que estranhezas, que grandes qualidades!

E tudo, sem mentir, puras verdades. (CAMÕES, 2006, p. 197-198)

Frente à visão do claramente visto, o poeta desafia o discurso dos sábios na escritura, que têm a arrogância de querer instituir a Verdade. Poeta com imensa bagagem de vida, Camões canta a dolorosa experiência do desconcerto, que é também ela a experimentação angustiosa e angustiada dos contrários, os quais, como vimos, estão sempre a gerar novos contrários, a sofrer a ação da mudança - que muda ela própria -, o que não permite a formulação de uma certeza. A poesia camoniana é altamente questionadora dos saberes cristalizados, das instâncias tradicionalmente aceites, e no lugar das pretensas convicções ela devolve ao seu leitor não a segurança de uma resposta mas uma extrema tensão, inscrita na impossibilidade de postular assertivamente quaisquer ideias. Trata-se pois de uma escritura eivada de perguntas-problema para as quais, no mais das vezes, não há o conforto de uma solução; escritura que prefere o terreno instável, movediço, das múltiplas possibilidades à inútil (por impossível) tentativa de chegada a uma resposta definitiva.

Ler Camões é partilhar da sua dor e estar na sua linguagem é experimentar o desassossego dos questionamentos, das perplexidades, do ilogismo, da arbitrariedade de um mundo desconcertado. Mas é este também, a meu ver, o aspecto delicioso, o lado absolutamente moderno e sedutor da sua poesia, gozosa na própria dor que escreve, assim como nos contrários que elenca e que quase sempre continuam a permanecer contraditórios, inconclusos. Helder Macedo, citando os estudos pioneiros de Jorge de Sena, acentua que "a poesia do homem complexo que foi Camões reflete um modo dialético de pensar" (2013, p. 29) e que tal dialética não se processa de modo evidente, ou seja, não é viabilizada por meio da neutralização dos termos em oposição numa síntese que moderadamente se fizesse conciliadora. Pelo contrário, diz ele, "no pensamento dialético de Camões as oposições frequentemente permanecem opostas e são assumidas como veracidades coexistentes por serem entendidas não tanto em termos de conflito quanto em termos de complementaridade" (2013, p. 29). Na mesma linha de pensamento, Jorge Fernandes da Silveira assinala que "Toda a plenitude camoniana é precária, breve, contraditória. Toda a leitura da dialética dos contrários em Camões, que se pretenda inteligente, terá de fugir das sínteses redutoras, terá de evitar as verdades incoerentes, porque absolutas" (2003, p. 42). 
As ponderações destes dois grandes camonistas apontam precisamente para a hipótese que aqui desejo levantar: a poesia camoniana expressa um veio filosófico ensaístico, construído na própria materialidade da sua escrita. Como sinalizei anteriormente na esteira dos versos de Alberto Caeiro (2005), Camões nunca compôs ensaios mas é como se os compusesse. Com efeito, discurso e contradiscurso são corolários do pensamento filosófico, bem como a base da construção de toda a filosofia ocidental. E muito modernamente Camões já descrê da possibilidade de acesso a uma verdade absoluta apontando deste modo para a relativização dos saberes, para a dissolução das certezas e para a construção de um conhecimento que erige empiricamente as suas verdades individuais: "verdades puras são, e não defeitos..." (2005, p. 117); "E tudo, sem mentir, puras verdades" (2006, p. 198), "puras verdades já por mim passadas" (2005, p. 229). E seria importante não esquecer que, embora plurais, cambiantes e fruto de uma experiência pessoal, as verdades do poeta não deixam todavia de ser universais, na medida em que comungam do amor - sentimento que atinge todos os homens -, e na medida em que muito conhecem da dor humana. Mas o mesmo amor que faz doer, sendo a si tão contrário (ensina-nos o próprio Camões), é aquele que também pode fazer sarar. Assim é que a dor do poeta seria capaz de curar as mágoas daqueles que sofrem de amor: amores magoados a curar outros amores magoados; cura que se logra com a inoculação da doença; medicina homeopática que trata a enfermidade mediante a introdução paulatina da sua substância causadora; veneno que é remédio; phármakon.

Pois meus olhos não cansam de chorar
tristezas, que não cansam de cansar-me;
pois não abranda o fogo em que abrasar-me
pôde quem eu jamais pude abrandar;
não canse o cego Amor de me guiar
a parte donde não saiba tornar-me;
nem deixe o mundo todo de escutar-me,
enquanto me a voz fraca não deixar.
E se nos montes, rios, ou em vales,
piedade mora, ou dentro mora Amor
em feras, aves, prantas, pedras, águas,
ouçam a longa história dos meus males
e curem sua dor com minha dor;
pois grandes mágoas podem curar mágoas. $(2005$, p. 161)

A longa história dos seus males será oferecida enquanto voz escrita, claro está, àqueles que por ela se interessarem. Nos seus versos de amor - sentimento que o matara ao longo de toda uma penosa existência gradualmente envenenada pela ação cruel do desconcerto -, Camões devolve a sua amarga experiência de vida (veneno) como phármakon (remédio). 
Em A farmácia de Platão Jacques Derrida (2015) estabelece um belíssimo intertexto com o Fedro e sinaliza o quanto o vocábulo grego phármakon é ambivalente, podendo ser traduzido quer por remédio, quer por veneno. Ambíguo, o phármakon é benéfico e maléfico, caminho e descaminho. Não por acaso o filósofo francês assinala como pontos-auge do referido diálogo a fábula das cigarras e o mito de Teuth, que apontam ambos para um mesmo conceito de desvio. Na primeira estória, Platão conta pela boca de Sócrates que, antes do nascimento das Musas, as cigarras eram em verdade homens. Com o nascimento delas (as Musas) surgira a atividade do canto e alguns humanos, absolutamente aturdidos de prazer, cantavam sem parar, esquecendo-se da comida e da bebida, sem contudo perceber que morriam. Desses homens mortos surgira posteriormente a espécie das cigarras que, como presente das Musas, muito compadecidas do seu tanto triste quanto belo fado, recebera o privilégio de uma vida não mais carente de alimento, podendo destarte cantar continuamente até à morte; na segunda estória, Sócrates especula sobre a origem da escrita. Diz a lenda que o deus egípcio Teuth, engenhoso inventor dos números, da geometria, da astronomia, do jogo do gamão e dos dados, criara ainda os caracteres da escrita, isto é, o alfabeto. Theuth, muito empolgado com as suas descobertas, decidira apresentá-las a Thamous, rei de todo o Egito, dizendo-lhe ser necessário disponibilizar o acesso desses recursos aos demais. Diante de tal apelo, Thamous questionara-o acerca da utilidade dos seus inventos, que então lhe foram apresentados um a um. Frente às explicações do deus, o rei julgava o que via e ouvia como bem ou mal fundado. Quando chegada a vez da escrita, esta recebera desaprovação total de Thamous, para a grande surpresa de Teuth, que afirmava com ela haver encontrado um remédio para a memória.

Ora, os dois os relatos apontam para os perigos da escrita, e a fábula das cigarras - que revela o antiquíssimo casamento entre a poesia e a música - é em verdade um prenúncio do mito de Teuth, quando a linguagem falada logra a possibilidade de ganhar um corpo escrito. Para Derrida, o mito das cigarras sinaliza a "incompatibilidade do escrito e do verdadeiro", pois “anuncia-se claramente no momento em que Sócrates se põe a contar como os homens são levados para fora de si, ausentam-se de si mesmos, esquecem-se e morrem na volúpia do canto" (2015, p. 13). E no caso específico do mito de Teuth a escrita é veementemente rechaçada porque, segundo o rei Thamous, com tal invento o deus Teuth descobrira um remédio não para a memória mas para a rememoração. Desta perspectiva, “[...] sob o pretexto de suprir a memória, a escritura faz esquecer ainda mais; longe de ampliar o saber, ela o reduz" (2015, p. 54-55), uma vez que não possibilita a reminiscência por meio do processo da maiêutica. Afinal, não nos olvidemos de que, para Platão, conhecer não é senão recordar. A escrita, diga-se, o phármakon, não é portanto inofensiva, assim como nenhum remédio o é, e não à toa ela é também única que, no contexto do Fedro, consegue desviar Sócrates do seu caminho, levando-o para o exterior 
dos muros de Atenas, numa aprazível excursão - etimologicamente uma saída para fora do curso - às margens do Ilisso. Ávido por ouvir as palavras escritas por Lísias em defesa dos não-amantes, Socrátes deixa-se seduzir, afastando-se do seu trajeto habitual.

Os perigos da escrita também se revelam em Camões. No soneto "Enquanto quis Fortuna que tivesse" o anúncio de tais perigos é proclamado em forma de discurso-epitáfio: "Porém, temendo Amor que aviso desse / minha escritura a algum juízo isento, / escureceu-me o engenho com tormento, / para que seus enganos não dissesse" (2005, p. 117). Ora, se no Fedro de Platão o rei Thamous rejeita a escrita - inicialmente apresentada como um remédio para a memória - porque a sua ação farmacológica sobre ela traria como efeito colateral precisamente a sua perda, nas Rimas de Camões o Amor decide obliterar o engenho do poeta pois a eficácia por ele desejada e anunciada já no segundo soneto das suas Rimas - "que dous mil acidentes namorados / faça sentir ao peito que não sente" (2005, p. 117) - afinal não se alcançaria. Noutras palavras: o hipotético desejo do poeta seria o de que os dois mil casos de amores acidentados que por ventura cantasse fossem capazes de sensibilizar até mesmo aqueles peitos mais duros, mais insensíveis, tornando-os predispostos à iniciação amorosa. Mas diante da leitura de amores tão desconcertados e, contudo, ainda ciosos de expressarem "brandas iras", "suspiros magoados" e inclusive uma impossível "pena ausente", os “juízos isentos", ou seja, aqueles que nunca amaram, em vez de se abrirem para as possibilidades do amor, se fechariam para ela. O texto de amor, cujo efeito esperado seria o do seu despertar, causaria contudo, nos não-amantes, exatamente o contrário do esperado: o não-amor. Discurso de amor que teria por resultado contraditório o desamor...

E se o phármakon platônico, como assinala Derrida, é ambivalente, a um só tempo substância e antisubstância, remédio e veneno, o amor, da perspectiva camoniana, enquanto discurso-desconcerto, é igualmente ambíguo: escravo que escraviza, liberdade que prende, prisão que liberta. Se do ponto de vista do Amor como deidade o discurso escrito sobre a sua ação na vida do poeta poderia causar como efeito lido nos juízos isentos o não-amor, para Camões o efeito das suas palavras escritas sobre os peitos magoados seria, ao contrário, benéfico, curativo. Numa poesia de dicção filosófica e ensaística como a dele, em que a dialética dos contrários é traço constitutivo da sua própria poética, o amor inscreve-se sob o signo da mutabilidade: ora cura, ora não sabe curar.

\section{CANTIGA}

a outra Dama que também estava doente

Deu, Senhora, por sentença

Amor, que fôsseis doente,

para fazerdes à gente

doce e fermosa a doença. 


\section{VOLTAS}

Não sabendo Amor curar,

foi a doença fazer

fermosa, para se ver,

doce para se passar.

Então, vendo a diferença

que há de vós a toda a gente,

mandou que fôsseis doente

para a glória da doença.

E digo-vos, de verdade, que a saúde anda envejosa, por ver estar tão fermosa em vós essa enfermidade.

Não façais logo detença,

Senhora, em estar doente, porque adoecerá a gente com desejos da doença.

Que eu, por ter, fermosa Dama, a doença que em vós vejo, vos confesso, que desejo de cair convosco em cama. Se consentis que me vença este mal, não houve gente de saúde tão contente como eu serei da doença. $(2005$, p. 49-50)

Jocosa - como a maior parte dos poemas da medida velha - esta cantiga estabelece uma séria discussão filosófica por meio de um jogo aparentemente leve e descontraído, assentado na estrutura de mote e glosa. E a questão aqui debatida parece ser mais uma vez de origem platônica. No Fedro Sócrates postula a ideia de o phármakon - entendido agora como medicamento e não como texto - ser nocivo ao corpo porque fruto do artifício. Contrariando a vida natural, inclusivamente a vida da doença, que tem a normalidade do seu curso desviada pela ação do remédio, o phármakon irrita, perturba este organismo vivo que, diz Derrida na lógica do pensamento de Platão, "é preciso deixar se desenvolver segundo suas formas próprias, seus ritmos e articulações específicas" (2015, p. 54). No que tange à cantiga de Camões o Amor, não sabendo promover a cura, ou seja, não sendo uma substância mas antes uma antissubstância, sabe todavia driblar a sua incapacidade curativa ao transformar em "doce e fermosa a doença”. E é mesmo interessante notar que da série de três redondilhas publicadas em 1595 - e destinadas todas elas a damas doentes - o amor, frente à manifestação da enfermidade, surge de modo deveras ambíguo, tal qual o phármakon platônico, e em duas destas três redondilhas ele é apresentado como um composto dotado de altas propriedades curativas. 
Na sua larga aventura pelo desconhecido, sempre em busca do conhecimento da vida, do mundo, da alteridade e do amor, Camões parece ter-se deparado por diversas vezes com a penosa experiência do desconcerto: "É tudo quanto sinto, um desconcerto" (2005, p. 118), diz o seu doloroso verso. O príncipe dos poetas conhecia muito da dor humana e generosamente decidira compartilhar o seu conhecimento com o outro convertendo o veneno das suas mágoas em texto capaz de curar. Na farmácia de Camões o antídoto para as dores de amor é elaborado mediante os ativos da própria toxina que mata. Como acentua Derrida: "O phármakón e a escritura são, pois, sempre uma questão de vida ou de morte” (2015, p. 61). A poesia camoniana, discurso-desconcerto, é também ela esta questão seríssima de vida ou de morte: phármakon.

\section{REFERÊNCIAS BIBLIOGRÁFICAS}

CAMÕES, Luís de. Rimas. Texto estabelecido e prefaciado por Álvaro J. da Costa Pimpão. Coimbra: Almedina, 2005.

CAMÕES, Luís de. Os Lusíadas. Edição organizada por Emanuel Paulo Ramos. Porto: Porto Editora, 2006.

DERRIDA, Jacques. A farmácia de Platão. Trad. Rogério da Costa. São Paulo: Iluminuras, 2015.

MACEDO, Helder. Camões e a viagem iniciática. Rio de Janeiro: Móbile, 2013.

PESSOA, Fernando. Obra poética. Introdução e notas de Maria Aliete Galhoz. Rio de Janeiro: Nova Aguilar, 2005.

PLATÃO. Fedro. Trad. José Cavalcante de Souza. São Paulo: Editora $34,2016$.

PLATÃO. O Banquete. Trad. Maria Teresa Schiappa de Azevedo. Coimbra: Edições 70, 2006.

PLATÃO. Fédon. Notas de Edson Bini. São Paulo: Edipro, 2006.

QUEVEDO, Francisco de. Antología poética comentada. Edição de Fernando Gómez Redondo. Madrid: EDAF, 2004.

SILVEIRA, Jorge Fernandes da. Discurso/desconcerto: alguns nós na literatura portuguesa. In: SILVEIRA, Jorge Fernandes da. Verso com verso. Coimbra: Angelus Novus, 2003, p. 41-58.

Recebido para publicação em 29/07/19 Aprovado em 09/04/19 


\section{NOTAS}

1 Professor Adjunto de Literatura Portuguesa da Universidade Federal do Rio de Janeiro (UFRJ) e Doutor em Literatura Portuguesa pela mesma universidade, com tese sobre a prosa e a correspondência literárias de Mário de Sá-Carneiro. Sua atuação profissional incide sobretudo no Decadentismo, no Modernismo e nos ecos do fim de século na literatura contemporânea quer no que se refere à narrativa quer no que tange à poesia. Tem publicações no Brasil e no exterior e é ainda co-organizador dos eventos "Jornada Mário de Sá-Carneiro: 100 anos depois" (UFF-UFRJ), "Há 100 anos Orpheu canta para Cleonice" (UFRJ), "100 Futurismo: a vez das Vanguardas" (UFRJ-UFF-UERJ) e "E, agora, José(s): 20 anos depois" (UFRJ-UERJ). De sua autoria pessoal, proferiu diversos cursos a respeito da geração de Orpheu no Centro Cultural Justiça Federal (CCJF), dentre os quais se destacam: "Por que ler Fernando Pessoa" e "Mário de Sá-Carneiro em foco". Atualmente, dirige o projeto de pesquisa "Camões no Oriente". 